ANNA TERESZKIEWICZ

Kraków

\title{
THE GENRE OF E-ZINES - IN THE SEARCH FOR CONVENTIONS
}

Keywords: genre, web genre, e-zine, website

\begin{abstract}
The aim of this article is to determine the basic genre conventions of electronic magazines, i.e. e-zines. The analysis illustrates the main characteristic features of e-zines, involving their function, format, content and functionality. The results of the analysis show that e-zines represent a group of heterogeneous forms, exploiting the conventions of other electronic genres, and thus creating hybrid constructions. The article presents a preliminary categorization of electronic magazines, carried out on the basis of the differences in content and in formatting techniques of these websites. The study illustrates as well the most recent trends in the form and content of electronic magazines.
\end{abstract}

\section{Introduction}

An e-zine (also webzine) is a short term for "electronic magazine". According to the definition, e-zines are magazines and / or publications issued in an electronic form (www.answers.com/topic/ezine, www.webopedia.com/TERM/E/e_zine.html). The majority of the explanations of the term do not reveal any significant details concerning the conventional structure of the genre in question. Therefore, considering the current web traffic and the myriad of the magazines and newspapers delivered in the electronic format, it becomes crucial to illustrate the existing tendencies in the construction of online publications. In the following article I examine the genre characteristics of e-zines in order to present the basic conventions concerning their purpose, form and content. 
The study is based on the analysis of 54 most popular e-zines, listed on the E-zine Directory web page. In my analysis I apply the approach towards the analysis of web genres proposed by Crowston and Williams (2000). According to this approach, the genre of a web page is defined on the basis of the properties of its purpose, content, form and functionality, the latter involving the affordances of the medium and its influence on the genre.

\section{Magazines on the web}

Online publications, such as newspapers, journals or magazines constitute an important and rich group of web genres. Due to the development of online services and a change in user preferences, nearly all print periodicals have nowadays their online counterparts. Additionally, there have been established numerous journals and publications issued exclusively on the web. The wide assortment of online publications and the relation between such magazines and print equivalents, however, significantly compounds the discussion of their genological specificity.

The research in this area typically reflects the above-mentioned duality of structures and differentiates between the so-called primarily and secondarily electronic publications, the latter involving the publications which have print counterparts. E-zines, in such taxonomy, are usually assigned to the group of primarily electronic magazines, i.e. magazines edited only on the web. According to Grzenia (2006), the basic difference between an e-zine and an electronic periodical is the primarily electronic, non-commercial and specialist nature of the former. Still, the review of the e-zines available on the web allows us to modify this statement in a few aspects. Many e-zines have acquired a commercial character, thus becoming a tool for gaining profits for their editors, many of them have expanded the area of interest, going beyond a single field of knowledge, a step taken in order to reach a wider audience. The only facet distinguishing e-zines among other periodicals is their primarily electronic existence.

\section{E-zine as a genre}

The analysed collection of e-zines proves that there is great diversity among these publications concerning their purpose, form and content. It turns out that e-zines constitute genologically complex forms, which defy easy categorization. The analysis of the sample allowed me to identify a few distinct trends followed in the composition of the specimens of this genre. Below, I present the basic conventions of e-zines concerning the sender, access options, purpose, form, content and functionality.

1. Sender

- personal (single or group) - e-zines constitute publications of single persons ( $45 \%$ in the analysed collection), or groups of individuals, i.e. of a board of editors (43\%), enthusiasts of particular fields of science, for whom the issuing of an e-zine is a matter of interest or hobby; 
- institutional - institutions constitute the second main group of e-zine publishers ( $12 \%$ within the analysed set). These include either commercial companies or non-profit organizations, which use the e-zine forms as a means of reaching a wider audience.

2. Access

There exist a few different options of obtaining access to e-zines. Typically e-zines are:

- available by subscription only (e.g. Before You Go, Learn Technical Writing);

- available online via a website only (e.g. Chizine);

- available both by subscription and online (e.g. Clarksworld, Abyss and Apex);

- available after downloading from a website (e.g. Janus Head).

3. Purpose

E-zines are issued to perform a number of different purposes. The analysed collection allowed us to isolate the following roles that e-zines play:

- commercial, advertising (e.g. Speakers Gold) - e-zines performing these functions are being issued mainly by companies and / or private entrepreneurs as a significant promotion tool, a means of advertising their products, but also an important form of maintaining contact with customers;

- informative, educational (e.g. Ex Libris) - the purpose of such e-zines is basically to present information or news;

- journalistic (e.g. Edge) - such e-zines present predominantly commentaries and personal opinions of the authors of e-zines;

- counselling (e.g. Relationship Rehab Gold, Australian Gardening Magazine) - the purpose of e-zines is frequently to give advice, suggestions or instructions. This concerns mainly e-zines focusing on specialist content and / or individual areas of knowledge;

- entertaining (e.g. Chizine, Strange Horizons) - e-zines are often issued to perform entertaining functions, offering articles to be read for pleasure, as a past-time.

I present these functions individually to show the different purposes behind the production of e-zines. Still, it is very frequent that an e-zine, analogically to traditional print magazines, fulfils several purposes, e.g. informative, entertaining and counselling, at the same time.

4. Form, content and functionality

As far as the form and content of e-zines are concerned, the analysis showed that e-zines do not comprise a homogeneous group. The set of web pages shows that e-zines assume different formats, applying the conventions of other web genres, thus forming borderline constructions. The examination of the web pages allowed the isolation of four basic sub-types of e-zines, based on the differences of form, i.e. the newsletter type, the blog type, the homepage type and the magazine type. The choice of a particular form is connected with a different content and the functionality offered by the e-zine. Therefore, I present these three properties together. 
a) The newsletter type

Within the analysed collection $29 \%$ of the e-zines were structured around the format of a newsletter. What becomes noticeable is a certain inconsistency in the genre terminology applied to these websites, as in many cases the term "e-zine" is used interchangeably with the term "newsletter", for instance:

Eee-zine: Want to keep up to date with the latest netbooks, updates and accessories? Then subscribe to The Eee-zine, ${ }^{1}$ our newsletter featuring the latest articles, news from netbooks, special offers, polls and information on Our Vision with the One Laptop Per Child Foundation.

Brain Facts E-zine: Hi, have you ever wished you had access to a resource that would give you the latest findings in educational research, news that would bring greater understanding of your students \& their problems? If so this newsletter is for YOU - its Brain Power Learning Group's educational Ezine. BPLG sends this ezine twice a month packed with cutting edge tips for greater success, ways to better understand your students' brains, hints to improve learning \& behaviour.

The inconsistency in naming is strongly tied with the similarity between the two genres in formatting techniques, as these e-zines assume the conventional format of a newsletter. The most typical structure of such e-zines includes the following components:

- a set of static data - these include the name of the e-zine stated on top of the page, the "unsubscribe" option, below comes the publication date, the number of issue and also editorial information;

- table of contents - which lists the content of the e-zine in a linear fashion in the form of hyperlinks to the individual components;

- sections of the e-zine - the title of the section and a short introduction to the contents of the section, concluding with a "Read more..." link leading to the full article;

- links to previous issues of the e-zine.

The functionality of these e-zines is quite low, including basically subscription options, e-mail contact and hypertext linking.

The two genres of a newsletter and an e-zine seem to be very close indeed with regards to structural conventions. However, there exist a few genological differences between these web page types, which deserve noting. E-zines, contrary to newsletters, constitute autonomous publications, issued regularly, containing complete articles. Newsletters conventionally represent only a component of a web page and act as a means of contact with the users, notifying them about the news or changes in the site. Newsletters are issued irregularly and, in contrast to e-zines, which may be downloaded or entered from the site, are always sent to the subscribers (www.cneb.pl/a/ ezin_newsletter.html?print=1).

My underlining. 
b) The blog type

The second formatting technique applied in the construction of e-zines is the use of the structure typical of a weblog genre. E-zines classified in this group, comprising $14 \%$ of the websites, assume the form of a blog, i.e. an internet diary, edited by an individual. The conventions which these e-zines share with the genre in question, and which allow us to situate them in this group, comprise the day-by-day structure of the e-zine, personal content of the e-zine and author-reader interaction. A further significant property of blog-like e-zines which they have in common with the blog genre, and which distinguishes them from other sub-types, is the fact that they are written in the 1st person singular.

The form and content of these magazines include the following components:

- daily sections - each section is marked by the date and the title of the section. Below these data comes the authorial commentary; each section is concluded with an invitation to the reader to provide a commentary on the content of the section;

- archives - offering former editions of the blog, usually arranged chronologically by date;

- links to external materials - these include links to outside content not associated with particular sections;

- personal information - including the data concerning the author of the e-zine and his/her interests.

The functionality of such e-zines is slightly higher than that of newsletters. They offer the option of downloading, commenting, registering on the site and also an RSS (Really Simple Syndication) subscription.

E-zines issued in this format, in contrast to other types, are updated frequently, usually daily, offering fresh content, which gives better chances to keep the readers by the site.

c) The homepage type

The design of the following type of e-zines is centred around the genre of a homepage, either personal or institutional in character. Within the analysed collection $27 \%$ of the e-zines were structured around this format. Access to these e-zines is achievable both through the homepage and through subscription, in which case users obtain a newsletter or an e-mail informing them about a new issue of the magazine, or through an RSS feed.

A distinctive property of these e-zines is a significant degree of genre hybridization within the site. Such e-zines offer very rich content, varied in scope and subject matter, including the following sections:

- featured content - comprising the best articles of the issue;

- regular columns by the authors contributing to the magazine - similarly to print journals, e-zines offer articles edited by regular contributors; 
- thematic sections - e-zines, analogically to traditional publications, are often organized around the paradigm of regular thematic sections, e.g. the sections of fiction, poetry and prose as in Chizine;

- news and events - this type of e-zines often broadens the scope of the information provided, performing the function of a news portal as well;

- links to authorial homepages and blogs - apart from regular columns users have access to personal websites of their favourite authors;

- a newsletter - which informs users about the changes in the website;

- video and audio files - homepage e-zines exploit the multimedia character of the internet;

- links to external materials - e-zines go beyond the content of particular issues offering users further resources;

- links to e-stores - links to e-stores constitute an opportunity of obtaining profits for the maintenance of the site.

Thus, the e-zines acquire the form of an abundant multimedia portal, a broad resource presenting a wide assortment of various types of information and materials, which is confirmed by the introduction to one of the magazines: e.g. "Australia's first national online gardening magazine and one of the first gardening sites anywhere on the net. It is a prime gardening resource, serving Australia and areas throughout the world enjoying a similar climate" (www.global-garden.com.au/).

The functionality of homepage-like magazines is very broad and includes the following options: e-mail contact, reader comments and questions, online submission of articles, joining the community centred around the e-zine, discussion fora, online chats, interactive contests for the authors of articles, audio and video files, RSS subscription and advertising.

d) The magazine type

The last type of e-zines, comprising $21 \%$ of the web pages, as the name suggests, comes closest to the genre of a print magazine itself. This type, however, seems to be the most complex with regards to the form and content, as it merges both the conventions of a traditional print magazine and the affordances of the web itself. In this type, we face a combination of a magazine with a homepage, the former constituting an individual component of the site, available for downloading or reading online, and the latter functioning as the basis for the publication of the magazine. Both the magazine and its homepage have interesting structures.

The form and content of the e-zine resemble a digitalized version of a print magazine. We might state that the magazine represents an electronic equivalent of a traditional publication. The magazine, as stated above, composes a separate element of the website, available for downloading, subscribing to, or entering from the site itself. The formats in which the magazine is edited differ and comprise the PDF (e.g. Janus Head, RV Lifestyles), the zip (e.g. Dragonia) or the html fomat (e.g. Specusphere). 
The relation between the website and the magazine is itself worth noting. The website seems to constitute a means of promoting the magazine, functioning as a gate to its contents. Its purpose is to attract the reader, keep him / her by the page, encourage to enter the magazine and become a regular subscriber. The page provides all the important editorial information, subscription options and also submission guidelines for potential authors. Besides, the website functions as an archive for the e-zine, offering links to previous issues of the magazine.

Analogically to the homepage type, these e-zines represent an example of genre hybridization. The website includes the components found in the previously described type of e-zines, i.e. links to a newsletter, to blogs and individual authors' homepages, and also other external links thematically associated with the site, as well as e-stores and advertisements.

The functionality of the magazine type of e-zines is comparable to the properties of the homepage type and includes search options, downloading, subscription via RSS or e-mail, e-mail contact, readers' submissions, commentaries, hypertext content, audio and video files, online interviews.

\section{Interactivity}

The general trend among e-zines, which is common to all the types, seems to be the emphasis put on interactive content. All the analysed magazines, to a greater or lesser extent, highlight the components focusing on author-reader interaction. These components, however, vary in type and quality. To the most frequent interactive elements belong the following:

- a "Letter from the Editor" section - a form of one-way contact with readers, describing the contents of the e-zine, its purpose, etc.; personal and friendly appeal of editors to readers helps to attract them and take a positive approach to the magazine;

- user account / login options - enable users to fully participate in intra-site activities; e-zines differ in the amount of the content available without registration; within the analysed collection $8 \%$ of the magazines were available only to the registered users; other e-zines required registration to post comments, send messages or download articles;

- a question / answer forum - which allows the editors see the problems users have;

- the opportunity to post tips for the e-zine - which gives readers a feeling of participation in creating or changing the magazine; editors may learn about readers' interests;

- online submissions from authors - which involves the invitation to provide content for the e-zine via e-mail, an easy and comfortable way of contributing to the magazine; this creates a feeling of openness to readers, who may feel encouraged to write;

- online chats and interviews - live interviews attract users to participate in the talk and add dynamism to the e-zine. 
The introduction of interactive elements plays a significant role in a successful functioning of the magazine. Apart from attracting users to the site, interactive content facilitates the establishment of a relationship between the editors and the users and also the development of trust readers have in the value of the magazine.

\section{Current trends}

The analysis showed that there are two further significant trends occurring in the life of this genre, i.e. podcasting ${ }^{2}$ and the evolution from "screen to page", that is from an online version to a print edition of the e-zine.

The first trend currently spreading among e-zines is the introduction of the option of podcasting. Podcasting involves the addition of audio files to a web site, with a further possibility of downloading these files onto an iPod or a different MP3 Player. Hence, the user has mainly two options of reaching a podcast:

- by entering a web site and listening to an audio file online;

- by subscribing to an RSS feed. This can be achieved using a software such as a podcatcher. This software reviews all the subscriptions of the user, tracing new files on the internet and downloading them automatically onto an iPod. The most popular podcatchers include iTunes or iPodder Lemon (escapepod.org/ podcasting). In that way, the user receives the audio versions of his / her favourite e-zines.

Within the collected e-zines, $13 \%$ offered a link to the podcasting option, whereas nearly $9 \%$ were structured solely in the podcast format.

Among the e-zines structured around this format we find for instance the Sundown Lounge, which describes itself as: "a weekly podzine ${ }^{3}$ of music, spoken word, progressive politics, weird science, and occasional vignettes from the west coast open mic scene, etc." (www.larrywinfield.com/sundownlounge.htm). Each issue of this podcast e-zine contains several audio files, the whole of around 50 minutes' length, which can be downloaded from the website or received in an RSS feed. The recordings concern different topics, being a mixture of political speeches, fiction, poetry and music.

A slightly different format of a podcast is exemplified by two e-zines: Escape Pod and Pseudopod - fiction and horror podcast magazines. These magazines are published weekly, each issue being structured around a single episode, or a short story, edited in an audio format.

It needs to be mentioned, though, that the use of the option of podcasting does not relate only to e-zines, but concerns the majority of web pages, e.g. blogs,

2 A podcast constitutes an interesting example of a currently emerging genre, not yet fully acknowledged and conventionalized. Its further development is undoubtedly worth observing.

3 The term "podzine" - an "iPod magazine" appeared twice in our collection, other e-zines applied the terms of a "podcast" or a "pod". Still, as the format currently undergoes development, it remains to be seen which term will gain the widest acceptance. 
personal homepages, many of which are beginning to exploit this form of contact with the user.

The other tendency which occurs among e-zines is the evolution from the digital version to a print edition of the magazine. This trend is particularly remarkable, since the typical course of evolution on which the recent analyses (e.g. Greer and Mensing 2004) have concentrated concerned the reverse trend, i.e. the movement "from page to screen", describing the digitalization of print publications. The analysis of the e-zines shows that the other course of change is as well becoming frequent on the web. One of the examples of such a transfer is the Void Magazine (www.ezine-dir.com/glinks/jump.cgi), whose print version was published after two years' online existence.

This evolution, however, concerns mainly the popular e-zines, with a high readership, those which achieve donations or sponsorships, due to which the publication is possible. The potential change in the genological complexity or in genre conventions occurring as a result of such evolution constitutes an interesting topic for further research concerning e-zines.

The analysis proves that the family of e-zines is considerably diversified and does not comprise homogeneous specimens. As we have seen, they take diverse forms and assume the conventions belonging to other genres, which leads to the formation of hybrid constructions. The assortment of electronic magazines is comparable to, or even richer than the variety of print publications. The basic reason for this situation lies in the medium of the internet which creates favourable conditions for the growth and development of innovative solutions and heterogeneous forms. The typology proposed in this paper should not be treated as fixed, but rather as open and flexible, allowing modifications and the introduction of further types occurring within the family of e-zines, which, as the tendencies show, undergo continuous transformations.

\section{References}

Crowston K., Williams M. 2000. Reproduced and emergent genres of communication on the world wide web. - Information Society 16. 3: 201-216.

Greer J., Mensing D. 2004. The evolution of online newspapers: a longitudinal content analysis, 1997-2003. - Newspaper Research Journal 25. 2: 98-112.

Grzenia J. 2006. Komunikacja językowa w Internecie. Warszawa.

Shepherd M., Watters C. 1999. The functionality attribute of cybergenres. - Proceedings of the 32nd Hawaii international conference on system science. [CDROM Collection]. Hawaii.

Watters C. R., Shepherd M. A. 1997. The digital broadsheet: an evolving genre. - Proceedings of the 30th Hawaii international conference on system science. [CDROM Collection]. Hawaii.

\section{Internet sources}

www.cneb.pl/a/ezin_newsletter.html? print=1 www.webopedia.com/TERM/E/e_zine.html www.answers.com/topic/ezine 


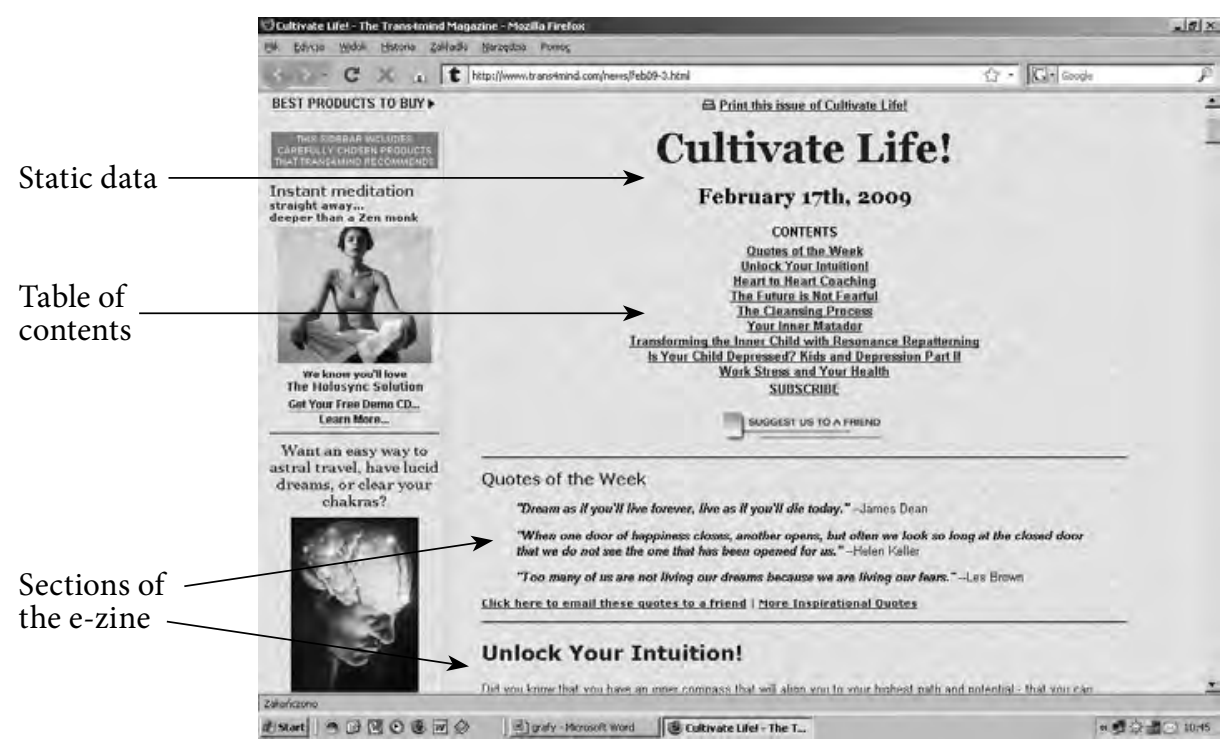

Fig. 1. An instance of a newsletter type e-zine.

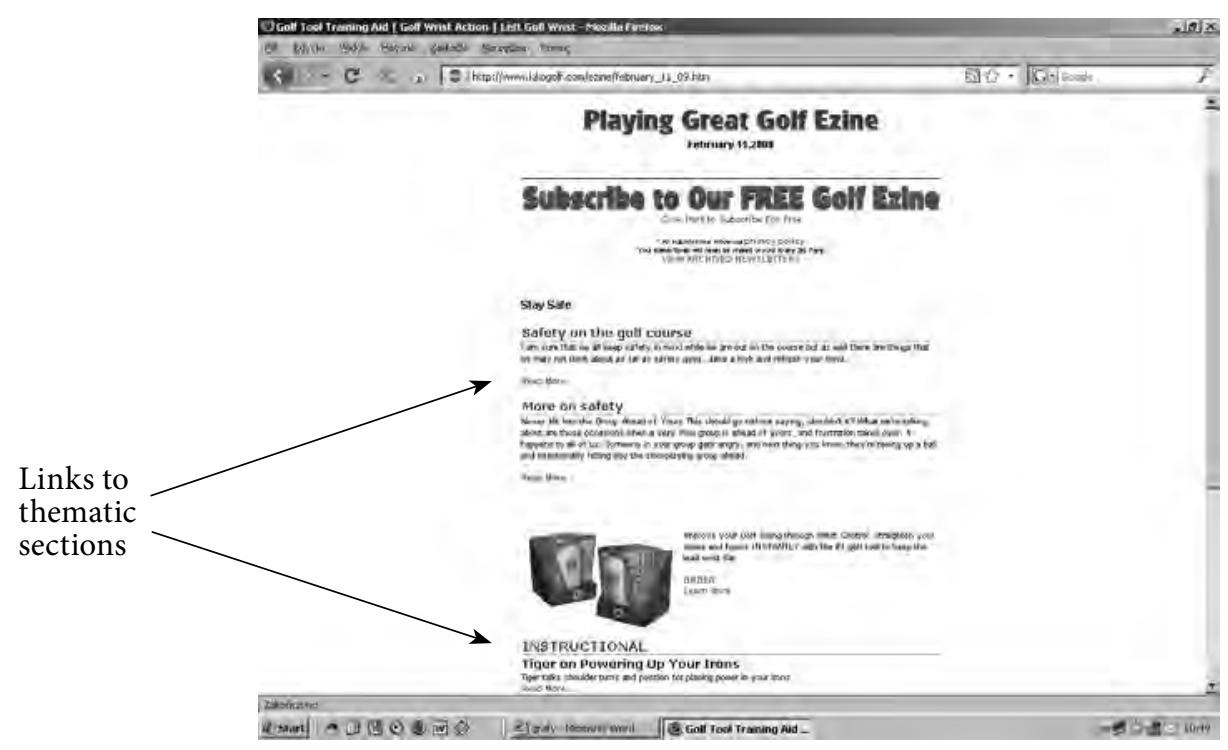

Fig. 2. A further instance of a newsletter type e-zine. 


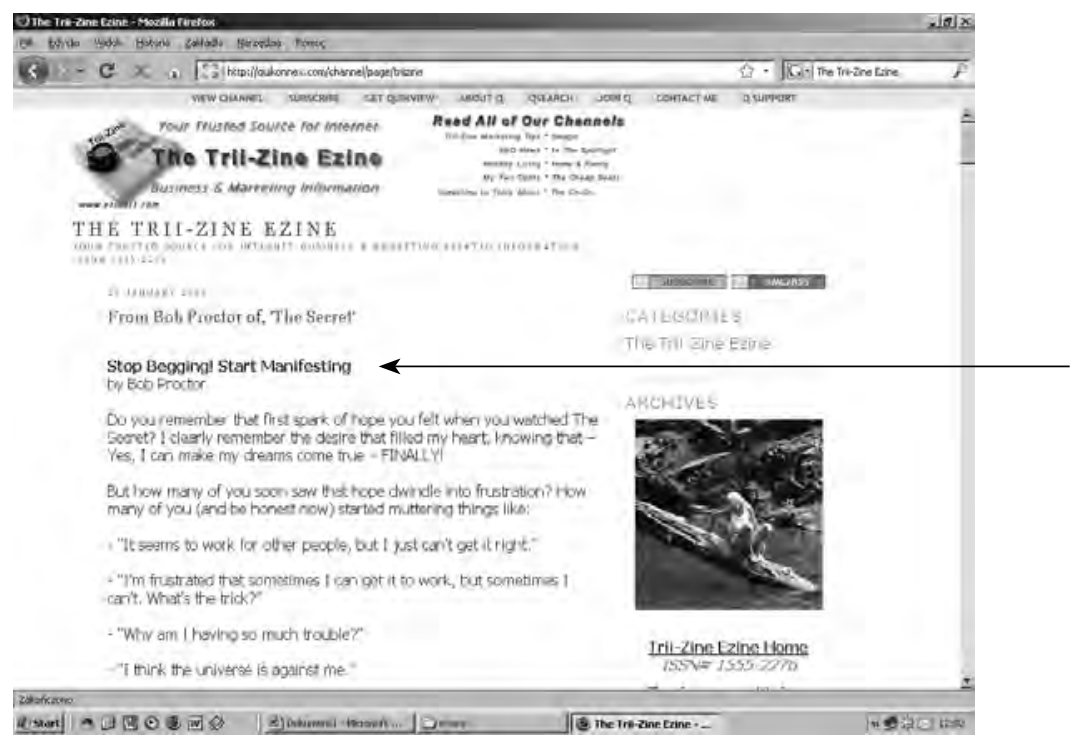

Daily

section,

$1^{\text {st }}$ person

narration

Fig. 3. An example of a blog type e-zine.

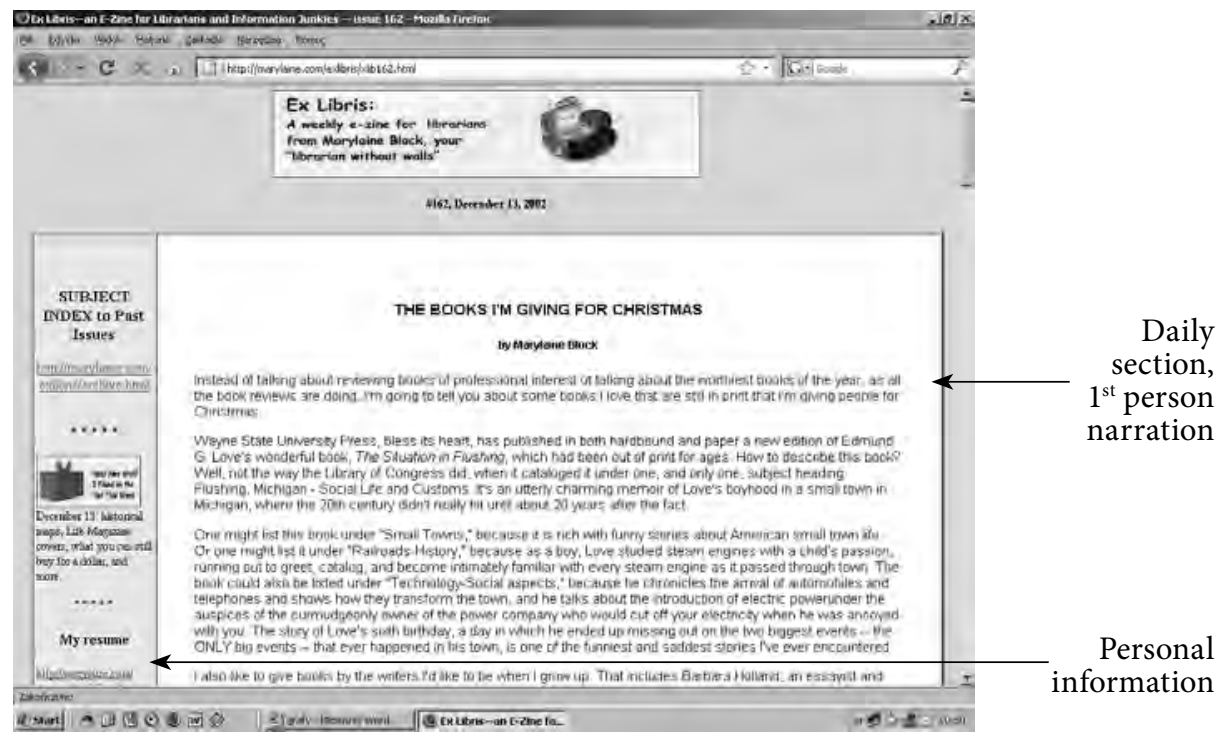

Fig. 4. A further instance of a blog type e-zine. 


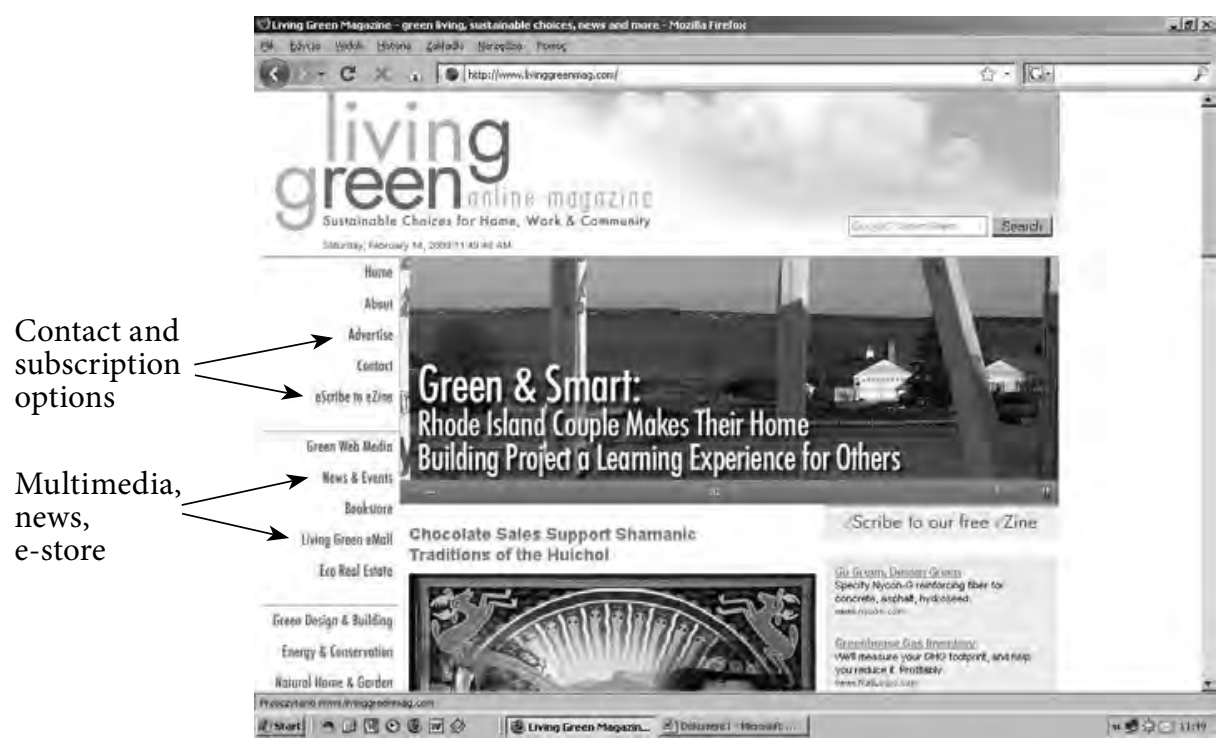

Fig. 5. A homepage type e-zine (top of the page).

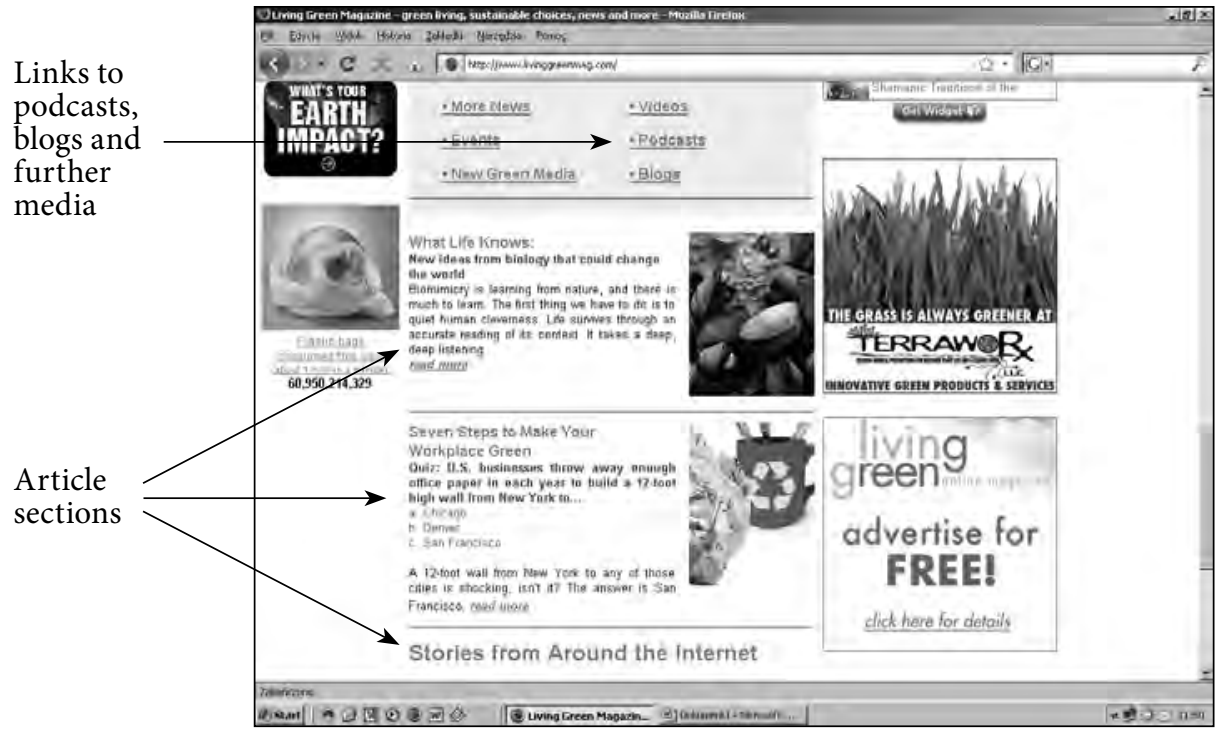

Fig. 6. A homepage type e-zine (bottom of the page). 


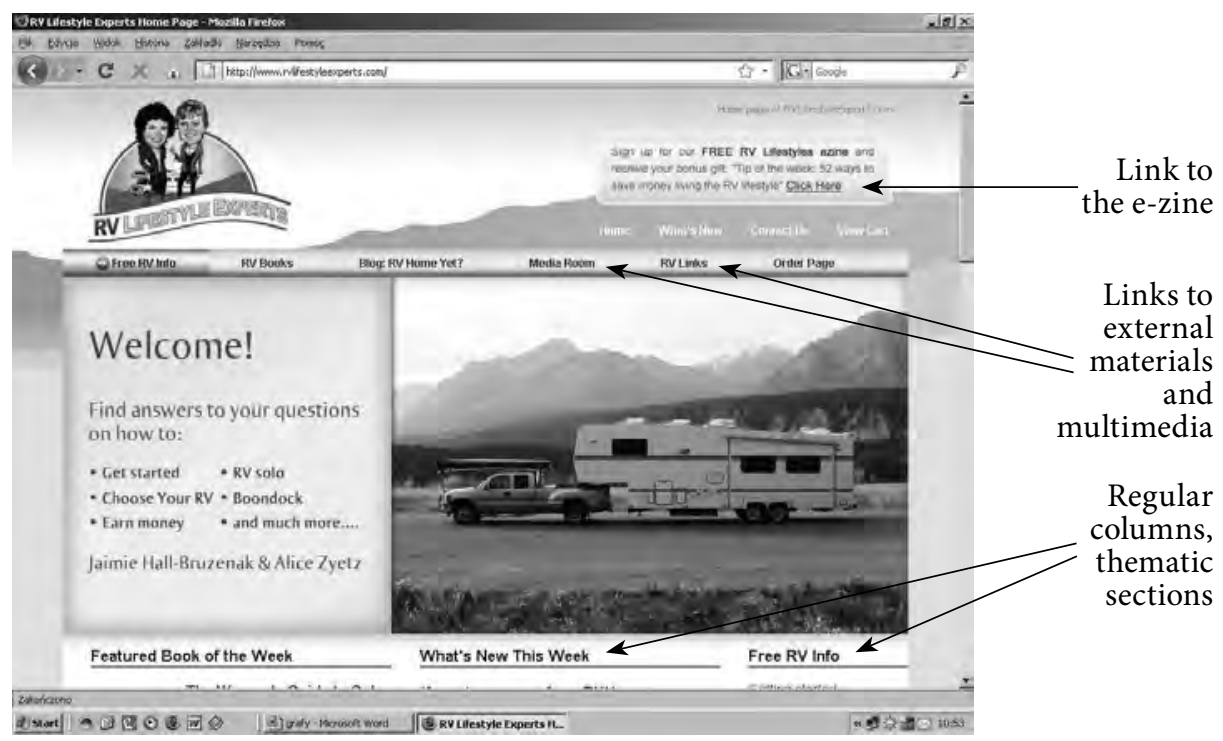

Fig. 7. A magazine type e-zine.

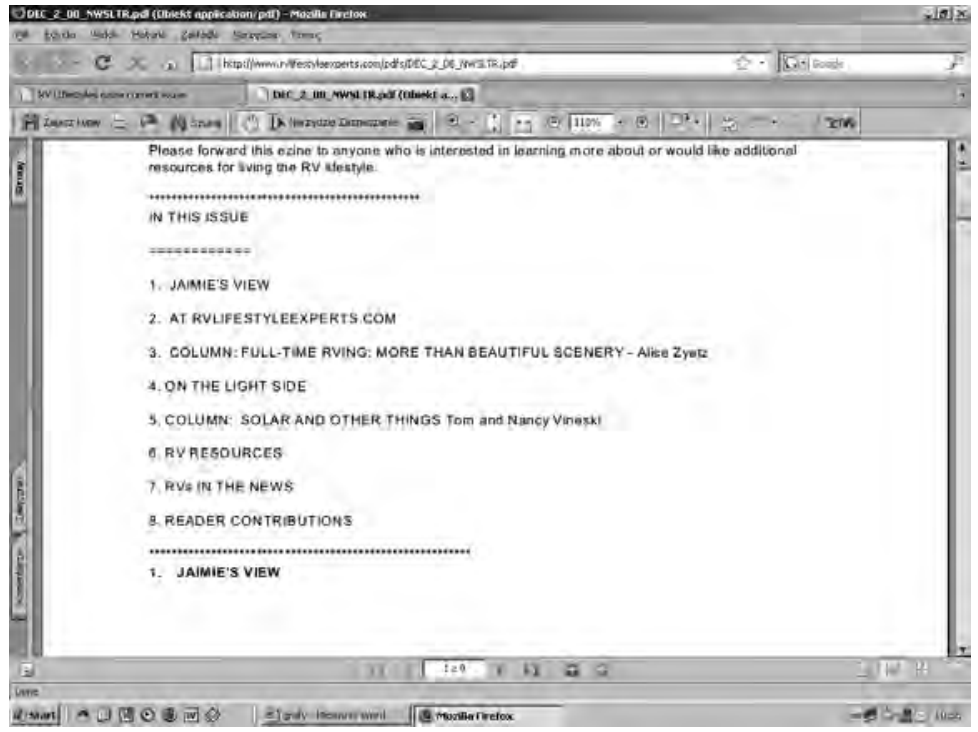

Fig. 8. A PDF version of an e-zine. 


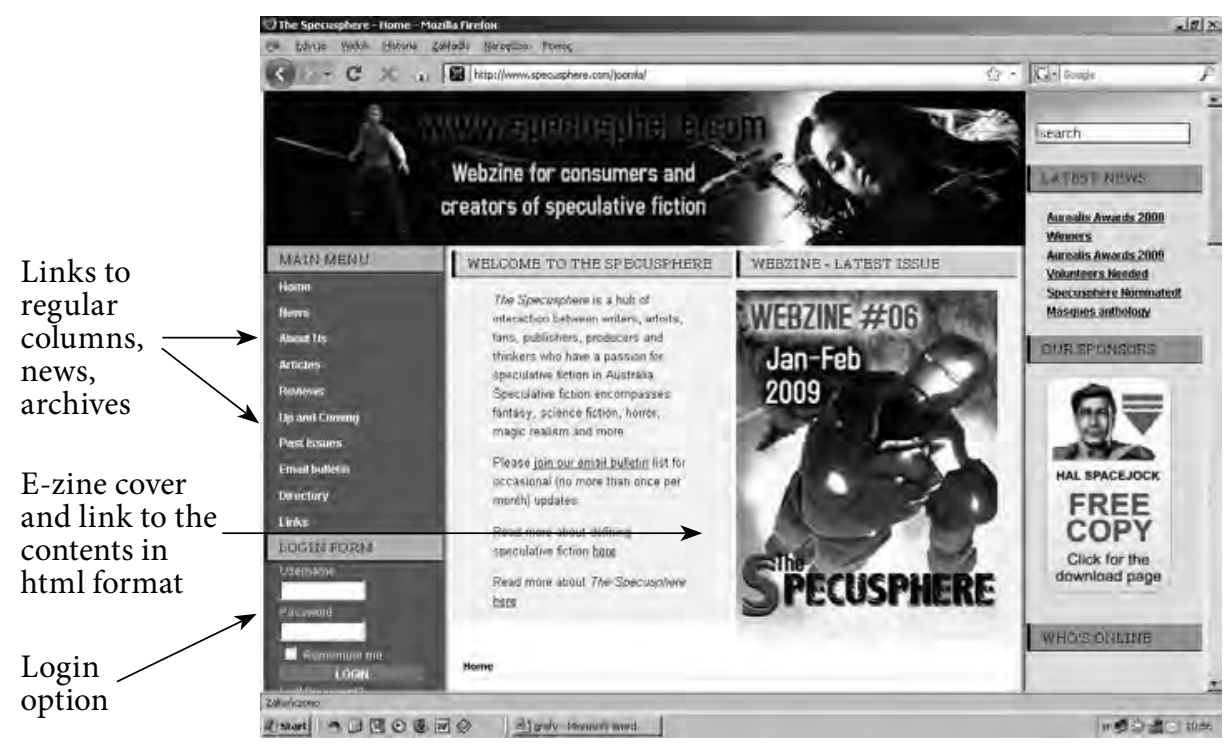

Fig. 9. A further instance of a magazine type e-zine.

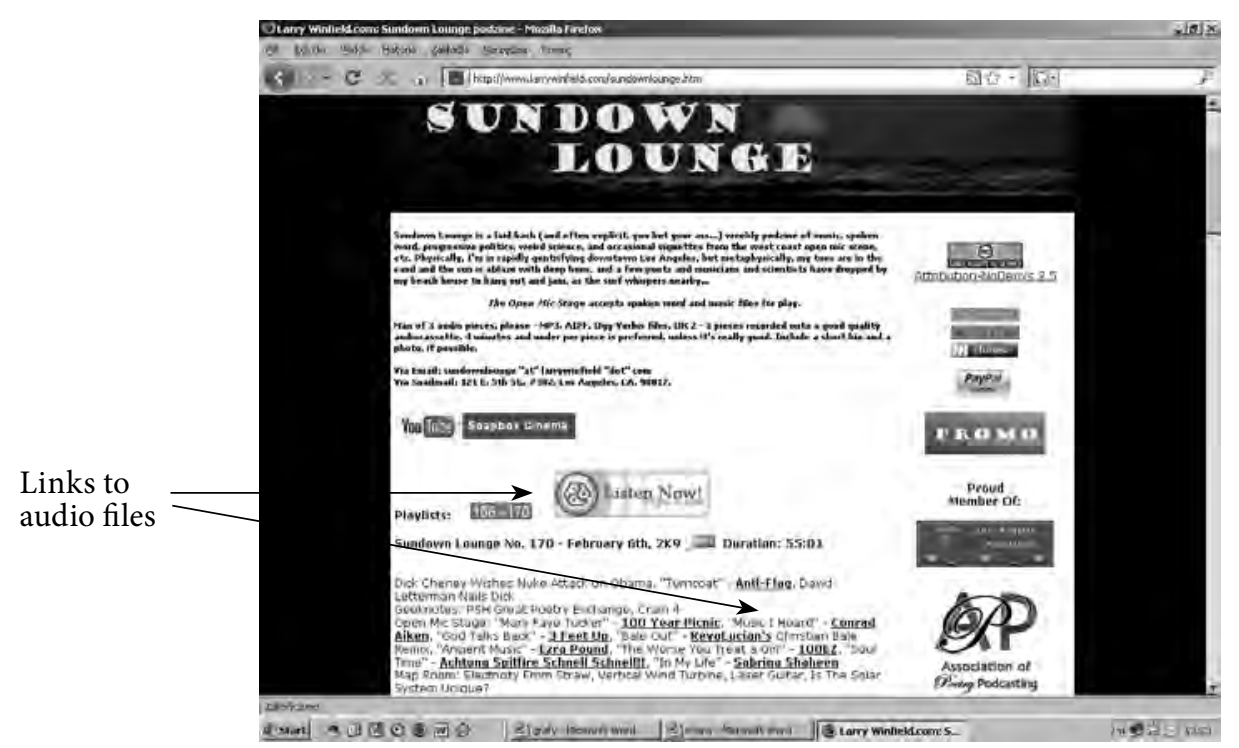

Fig. 10. An instance of a podcast e-zine. 


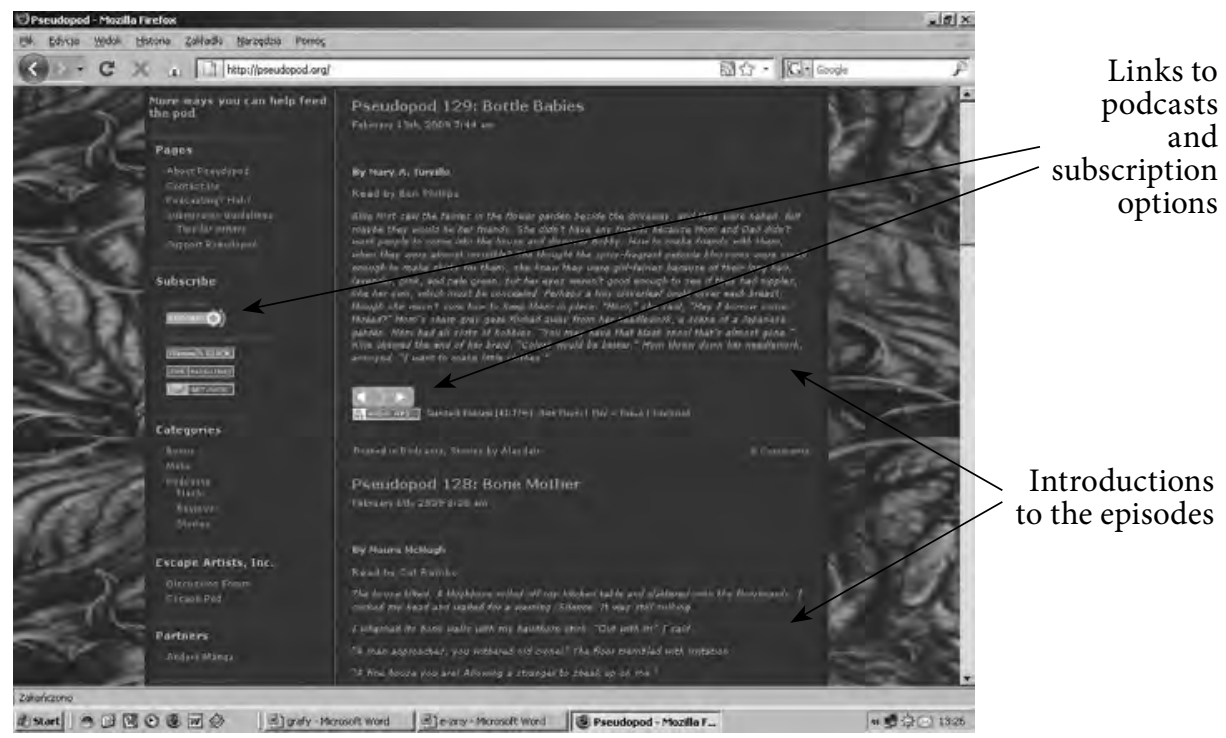

Fig. 11. A further example of a podcast magazine. 